\title{
Finding the Sweet Spot: the Last Blood Glucose Measured in the Hospital and 30-Day Outcomes-a Retrospective Study
}

\author{
Nishant Sahni, MD, MS ${ }^{7}$, Gyorgy Simon, $P h D^{2}$, and Rashi Arora, $M D^{3}$ \\ 'Division of General Internal Medicine, University of Minnesota, Minneapolis, MN, USA; ${ }^{2}$ Institute for Health Informatics, University of Minnesota, \\ Minneapolis, USA; ${ }^{3}$ Health Partners, Saint Paul, MN, USA.
}

J Gen Intern Med 34(4):510-2

DOI: $10.1007 / \mathrm{s} 11606-018-4740-\mathrm{Z}$

(C) Society of General Internal Medicine 2018

\section{INTRODUCTION}

Even though clinicians caring for hospitalized patients frequently encounter abnormal glucose values at hospital discharge, and hyperglycemia is associated with worse hospital outcomes, little data exists on the prognostic relevance of the last blood glucose (BG) measurement in the hospital. ${ }^{1-3}$ We parse the association between the last BG measurement in the hospital and 30-day readmission/ mortality and test the following hypotheses: (1) Patients with dysglycemia on the last BG measurement in the hospital experience higher rates of 30-day death and readmissions. (2) The risk increases with the severity of dysglycemia (defined as glucose $>100 \mathrm{mg} / \mathrm{dL}$ or $<70 \mathrm{mg}$ / $\mathrm{dL})$ regardless of diagnosis of diabetes mellitus (DM).

\section{METHODS}

We obtained institutional review board approval from the University of Minnesota and created an electronic medical record (EMR)-derived dataset of 126,527 emergent hospital admissions for 67,308 patients within a six-hospital network in the Twin Cities area, MN, from 2012 to 2016. Patients were excluded if they were non-emergent admissions, were less than 18 years of age, did not consent to their medical record being used for research purposes, had less than 31 days of follow-up mortality data, or were not Minnesota residents. Data were collected on patient characteristics, comorbidities, and outcomes. Among 67,308 patients with multiple hospitalizations, we randomly selected a single encounter for each patient to minimize bias in outcome assessment. All laboratory and physiologic data was time-stamped and was obtained within at least $24 \mathrm{~h}$ of the end of the hospitalization. Blood glucose values obtained from finger stick blood tests or as part of a laboratory panel were included in the dataset. The last available measurement during an encounter was used for analyses. Blood glucose values were categorized as follows: < $70 \mathrm{mg} / \mathrm{dL}, 70-100 \mathrm{mg} / \mathrm{dL}, 100-200 \mathrm{mg} / \mathrm{dL}, 200-300 \mathrm{mg} /$ $\mathrm{dL}, 300-400 \mathrm{mg} / \mathrm{dL}$, and $>400 \mathrm{mg} / \mathrm{dL}$.

Published online December 14, 2018
The relative risk (RR) of 30-day death or readmission within each range of $\mathrm{BG}$ was modeled using Poisson regression with robust error variance. The primary outcome was death or readmission within 30 days of the index hospitalization; inpatient deaths were excluded to examine postdischarge outcomes. We adjusted the models for age, sex, race, AHRQ comorbidities, BMI, and length of stay. The $70-100 \mathrm{mg} / \mathrm{dL}$ range was treated as the reference range for the RR calculation. Analysis was done using R-Studio. R packages - tidyverse, icd, nephro, ggplot2, mcgv, sandwich, lmetest, and tableone-were used.

\section{RESULTS}

We describe the patient demographic, clinical, and laboratory characteristics in Table 1 . The lowest rate of postdischarge 30-day readmission/death was observed when the final BG was within 70-100 $\mathrm{mg} / \mathrm{dL}$ (6.1\%; Fig. 1). The adjusted RR of post-discharge events rose in tandem with the final BG (Fig. 1, 100-150 mg/dL-RR, 1.08; $150-200 \mathrm{mg} / \mathrm{dL}-\mathrm{RR}, 1.24 ; 200-300 \mathrm{mg} / \mathrm{dL}-\mathrm{RR}, 1.48$; $300-400 \mathrm{mg} / \mathrm{dL}-\mathrm{RR}, 2.16$ ) and plateaued at maximal odds when the final BG was greater than $400 \mathrm{mg} / \mathrm{dL}$ (Fig. 1; RR, 2.51). Patients with hypoglycemia (final BG values of less than $70 \mathrm{mg} / \mathrm{dL}$ ) also had a higher risk (Fig. 1; RR, 1.87). Hyperglycemic patients who had a diagnosis of DM during the encounter had a significantly lower rate of 30day adverse events than those who did not carry a DM diagnosis (100-150 mg/dL: $9.6 \%$ versus $8.1 \%, 150-$ $200 \mathrm{mg} / \mathrm{dL}: 23.2 \%$ versus $16.9 \% ; p<0.05)$.

\section{DISCUSSION}

We found a progressively higher risk of 30-day readmission/death after hospital discharge as the last hospital BG deviated from the $70-100 \mathrm{mg} / \mathrm{dL}$ range. Twentyfive to fifty percent of hospitalized patients meet the criteria for DM, pre-DM, or hyperglycemia, but these conditions commonly go unrecognized. ${ }^{2}$ Relatively "mild" elevations in the final $\mathrm{BG}$ - especially when unaccompanied by an explicit diagnosis of DM-were associated with a higher risk of 30-day mortality and readmission in our dataset. While we observed increased risks at deviations 
Table 1 Clinical, Demographic, and Laboratory Characteristics of the Cohort. Stratified by Death or Readmission Within 30 Days. Median Values With Interquartile Ranges (Within Brackets) Are Reported for the Continuous Variables. Proportions With Percentages (Within Parenthesis) Are Reported for the Categorical Variables

\begin{tabular}{|c|c|c|c|}
\hline & \multicolumn{2}{|c|}{ Stratified by death or readmission within 30 days } & \multirow[b]{2}{*}{$p$ value } \\
\hline & $\begin{array}{l}\text { Patients who did not have } 30 \text {-day death } \\
\text { or readmission within } 30 \text { days }\end{array}$ & $\begin{array}{l}\text { Patients who had death } \\
\text { or readmission within } 30 \text { days }\end{array}$ & \\
\hline Number of patients & 60,095 & 7213 & \\
\hline Age (years) & $60.08[43.72,75.31]$ & $71.65[58.53,83.86]$ & $<0.001$ \\
\hline Albumin $(\mathrm{g} / \mathrm{dL})$ & $3.50[3.00,4.00]$ & $2.70[2.20,3.30]$ & $<0.001$ \\
\hline Total bilirubin (mg/dL) & $0.60[0.40,0.90]$ & $0.80[0.40,1.50]$ & $<0.001$ \\
\hline Creatinine $(\mathrm{mg} / \mathrm{dL})$ & $0.81[0.67,1.01]$ & $1.00[0.72,1.59]$ & $<0.001$ \\
\hline Blood glucose $(\mathrm{mg} / \mathrm{dL})$ & $101.00[90.00,121.00]$ & $111.00[93.00,141.00]$ & $<0.001$ \\
\hline Sodium $(\mathrm{mEq} / \mathrm{L})$ & $139.00[137.00,141.00]$ & $139.00[136.00,142.00]$ & 0.432 \\
\hline Hemoglobin $(g / d L)$ & $12.10[10.30,13.60]$ & $10.20[8.80,11.90]$ & $<0.001$ \\
\hline Platelet count $\left(\times 10^{9}\right.$ per liter $)$ & $210.00[164.00,264.00]$ & $185.00[121.00,256.00]$ & $<0.001$ \\
\hline Length of stay (days) & $3.00[2.00,4.00]$ & $4.00[2.00,7.00]$ & $<0.001$ \\
\hline \multicolumn{3}{|l|}{ Discharge disposition (\%) } & $<0.001$ \\
\hline Acute rehab facility & $864(1.44)$ & $51(0.71)$ & \\
\hline Expired & $0(0.00)$ & $2239(31.04)$ & \\
\hline Home IV drug therapy & $573(0.95)$ & $55(0.76)$ & \\
\hline Home or self-care & $40,923(68.10)$ & $1690(23.43)$ & \\
\hline Home health care service & $5234(8.71)$ & $682(9.46)$ & \\
\hline Hospice/home & $431(0.72)$ & 489 (6.78) & \\
\hline Left against medical advice & $594(0.99)$ & $45(0.62)$ & \\
\hline Other & $1567(2.60)$ & $359(4.98)$ & \\
\hline Psychiatric hospital & $703(1.17)$ & $35(0.49)$ & \\
\hline Short-term hospital & $1203(2.00)$ & $335(4.64)$ & \\
\hline Skilled nursing facility & 8003 (13.32) & $1233(17.09)$ & \\
\hline BMI $\left(\mathrm{kg} / \mathrm{m}^{2}\right)$ & $27.26[23.42,32.12]$ & $26.32[22.40,31.18]$ & $<0.001$ \\
\hline Sex $=$ male $(\%)$ & $28,906(48.10)$ & $3636(50.41)$ & $<0.001$ \\
\hline \multicolumn{4}{|l|}{ Race $(\%)$} \\
\hline White & $50,831(84.58)$ & $6244(86.57)$ & $<0.001$ \\
\hline
\end{tabular}

from 70 to $100 \mathrm{mg} / \mathrm{dL}$, the target range for pre-meal glucose is typically considered $<140 \mathrm{mg} / \mathrm{dL}$ for hospitalized patients. ${ }^{4}$ Lower target values than this have shown negative outcomes in multiple studies. ${ }^{5}$

Although we adjusted for comorbidities, our findings could be confounded by unmeasured medical or social factors in dysglycemic patients. Studying the effectiveness of interventions that improve the identification and management of inpatient dysglycemia-such as automated flagging of asymptomatic random BG values of $\geq$ $100 \mathrm{mg} / \mathrm{dL}$ - may improve post-discharge outcomes and answer some of the questions raised by our data. ${ }^{6}$
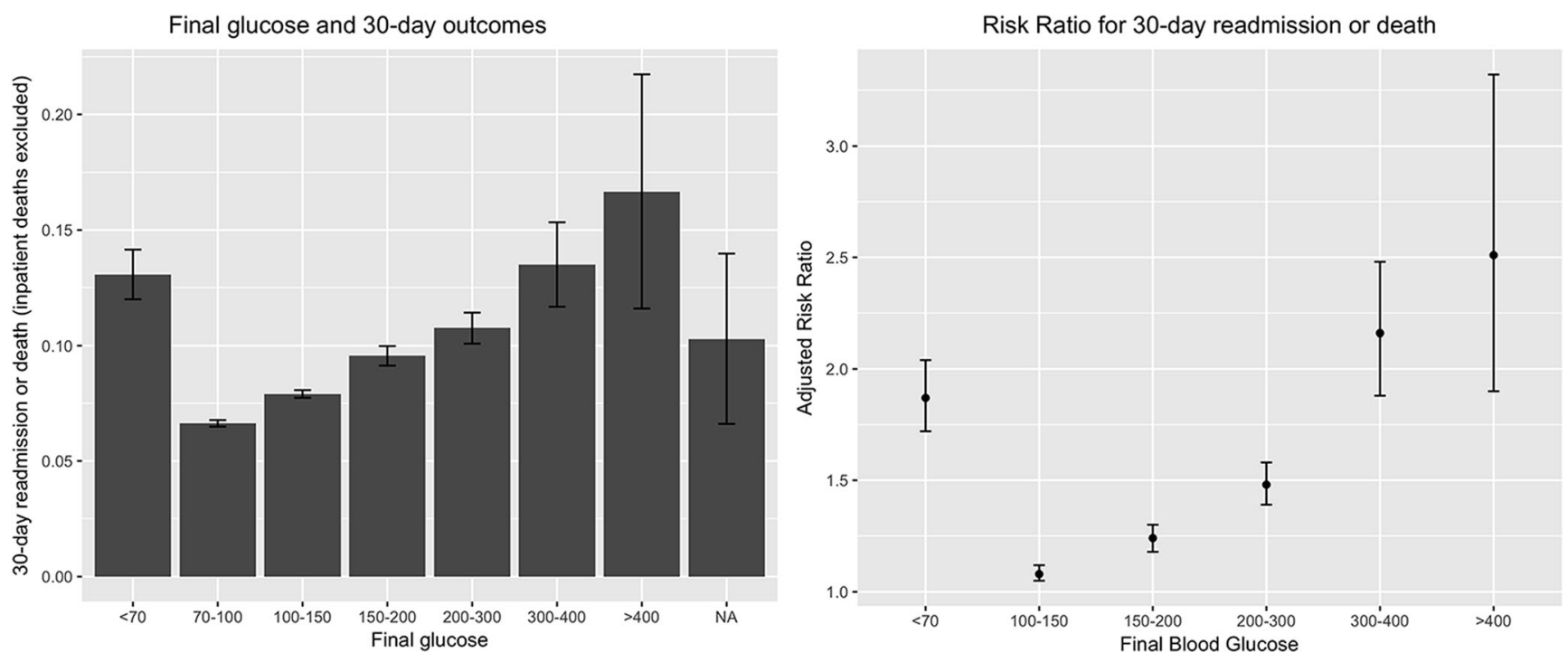

Figure 1 The last blood glucose measured during a hospitalization and 30-day mortality and readmission. Left panel: proportion of patients who died or readmitted within 30 days of the hospitalization across the range of final BG values. Error bars represent the $95 \%$ standard errors around the proportion estimate. Right panel: risk ratio of 30-day death or readmission after hospital discharge compared to reference risk when the last BG is within the $\mathbf{7 0 - 1 0 0 ~} \mathrm{mg} / \mathrm{dL}$. Ninety-five percent confidence intervals of the estimates are indicated by the error bars. 
Funding Sources: Resources used for the research reported in this publication were supported by the National Center for Advancing Translational Sciences of the National Institutes of Health Award Number UL1TR000114.

Corresponding Author: Nishant Sahni, MD, MS; Division of General Internal Medicine, University of Minnesota, 420 Delaware Street SE, MMC 741, Minneapolis, MN 55455, USA (e-mail: nishant. sahni@gmail.com).

Author Contribution Dr. Sahni participated in study design, data analysis, and manuscript preparation. Dr. Arora participated in manuscript preparation. Dr. Simon participated in data analysis.

\section{Compliance with Ethical Standards:}

Conflict of Interest: The authors declare that they do not have a conflict of interest.

Disclaimer: The content is solely the responsibility of the authors and does not necessarily represent the official views of the National Institutes of Health.

\section{REFERENCES}

1. Umpierrez GE, Isaacs SD, Bazargan N, You X, Thaler LM, Kitabchi AE. Hyperglycemia: An Independent Marker of In-Hospital Mortality in Patients with Undiagnosed Diabetes. J Clin Endocrinol Metab. 2002;87(3):978-982. https://doi.org/10.1210/jcem.87.3.8341.

2. Malaskovitz J, Hodge C. Addressing glycemic targets from diagnosis to discharge. Diabetes Spectr. 2014;27(3):169-173. https://doi.org/10. 2337/diaspect.27.3.169.

3. Falciglia M, Freyberg RW, Almenoff PL, D'Alessio DA, Render ML. Hyperglycemia-related mortality in critically ill patients varies with admission diagnosis. Crit Care Med. 2009;37(12):3001-3009. https://doi.org/ 10.1097/CCM.0b013e3181b083f7.

4. Umpierrez GE. Management of Hyperglycemia in HospitalizedPatients in Non-Critical Care Setting: An EndocrineSociety Clinical Practice Guideline. $J$ Clin Endocrinol Metab. 2012;97(1):16-38.

5. Yamada T, Shojima N, Noma H, Yamauchi T, Kadowaki T. Glycemic control, mortality, and hypoglycemia in critically ill patients: a systematic review and network meta-analysis of randomized controlled trials. Intensive Care Med. 2017;43(1). https://doi.org/10.1007/s00134-016-4523-0.

6. Bowen ME, Xuan L, Lingvay I, Halm EA. Random blood glucose: a robust risk factor for type 2 diabetes. J Clin Endocrinol Metab. 2015;100(4):15031510. https://doi.org/10.1210/jc.2014-4116. 